\title{
Discussion on the application of VR, AR and MR technology in landscape architecture
}

\author{
Hongbin Lee ${ }^{1, a}$, Sheng $\operatorname{Lu}^{1,2, b}$
}

1Beijing University of Agriculture College of landscape architecture, Beijing, 102206, China;

${ }^{2}$ Beijing Laboratory of Urban and Rural Ecological Environment, Beijing, 100083, China.

a1063705612@qq.com, b buc01@126.com

Key words: Virtual Reality, Augmented Reality, Mixed Reality, Landscape Architecture.

\begin{abstract}
In the process of digital propulsion, virtual reality, augmented reality and mixed reality technology have been developed rapidly. However, there are no systematic research results in two aspects, which are how to applicate the technique in landscape design and whether the technology makes the landscape architecture more scientific or not [1]. Comprehensively, with the contrastive analysis in conception, equipment, technical characteristics and working operation among virtual reality, augmented reality and mixed reality technology, the thesis aims at exploring the feasibility of virtual technology in landscape architecture design, striving to seek a new development for landscape design in this changeable digitalization.
\end{abstract}

\section{Introduction}

Digital development has brought great changes for or the human's work and life, in the future, the general public will live in a digital world, where all things will be realized through the wealth of digital services, and the boundaries between the real and the digital world will become more obscure [2]. Artificial intelligence and machine learning will gradually expand and extend to the service and things supported by technology, at the same time, the development of virtual reality, augmented reality and mixed reality will make a greater contribution in landscape design.

\section{The perception and technical characteristics of VR, AR and MR}

(1) Virtual Reality (VR) technology is a comprehensive information technology designed by Jaron Lanier, founder of VPL, in the 1980s [3]. Its purpose is to generate a 3D virtual environment in the computer. Through specific professional sensing devices, the users can get into the virtual world, interact with virtual objects and feel the tactual, visual and auditory illusions and feeling personally on the scene.

The dominant in the virtual reality system is people, through providing a kind of intuitive and natural means of real-time interaction, the system is to achieve the user's real experience for the scenario simulation and natural human computer interaction by computing interfaces. Its basic characteristics are immersion, interaction and imagination [4]. Immersion refers to the degree of awareness when a user is exposed to a virtual environment; interaction refers to the perception and feedback of the user's ability to manipulate objects in a virtual environment in a human way; Imagination refers a re-creation of the environment with their own imagination and creativity in the virtual system. Its core technology mainly includes three- dimensional computer modeling technology, stereo display and stereo technology, and three-dimensional image real-time generation technology.

(2) Augmented Reality (AR) technology, a kind of computer application and human-computer interaction technology based on the virtual reality, it uses computer technology to apply virtual information to the real world, where real environment and virtual objects are superimposed on the same image or space at the same time [5]. Augmented reality is based on the real world, emphasizing the virtual technology is in the service of truth. The biggest characteristic is that the users and the real 
world are not isolated, instead, the real and the virtual world are integrated, allowing the user to interact with the two different fields.

Augmented reality is not confined to the increase of the visual scene of reality, the information that is perceived in the virtual appliance, by transformation, in a way that human beings can perceive (sound, image, touch, etc.) is stacked to the user of the real scene to realize the enhancement effect of reality. The key technologies of augmented reality include tracking and positioning technology, user interaction technology, virtual fusion technology and system display technology. In augmented reality, users can refer to the real world while seeing virtual objects and can distinguish them.

(3) Mixed reality (MR) technology, is a mixture of VR and AR. It will be a new visual environment created by mixing real and virtual worlds, and the virtual reality information can be loaded to experience in the real world, to implement the seamless joint between virtual and Reality, to provide users new way of interaction between the virtual and real worlds [6].

The core of the mixed reality technology is to improve the user's perception of the real environment through additional information, and realize the overlay of real and virtual data. User can maintain itself for the connection between real and virtual, and can adjust two environments. According to their own needs. Mixed reality combines the real world with the virtual world perfectly, and achieves the true and unreal effects [7].

\section{Virtual reality and Landscape architecture}

Landscape design experience from the concept of text (language) to two-dimensional drawings (painted) to the sand table model (3D model) and computer aided design now. However, they are generally unable to accurately use dynamic way to describe the defects of landscape design, and also cannot be completely real-time communication, which causes that the feasibility of the scheme is greatly reduced, bring great trouble to the landscape design workers.

The application of virtual reality technology in landscape design, based on showing the characteristics of real-time 3D interaction, offers a new interactive interface design different from traditional one, designers can experience their own design of 3D virtual landscape space, edit the real-time editing landscape elements and control the specific parameters in the scene, strive to achieve the humanization and scientization, which provide strong technical support for the design idea and the corresponding performance.

Landscape architecture in the construction of a virtual reality system (figure 1) is mainly based on the principles of science, authenticity and professional, the mode of standardization to make the system reasonably on the basis of complete function. The system mainly includes input module, test module and output module. The input module mainly provides input for information such as parameterized scene model; the virtual test module is composed of interface module, analysis module and run sensing module. Interface module is mainly uses the simulation, the running environment and the sensor to communicate with the user; The analysis module mainly aims at the landscape elements such as plants and buildings and the environmental factors such as sunshine; Run sensing module is to provide users with a realistic virtual environment, and give feedback about the model and scene in the state of the test process to the user timely and make corresponding adjustments. In the final output stage, according to the experience in the virtual scene and feedback of information, comprehensively evaluate and adjust the optimized design and make the design more economical [8]. 


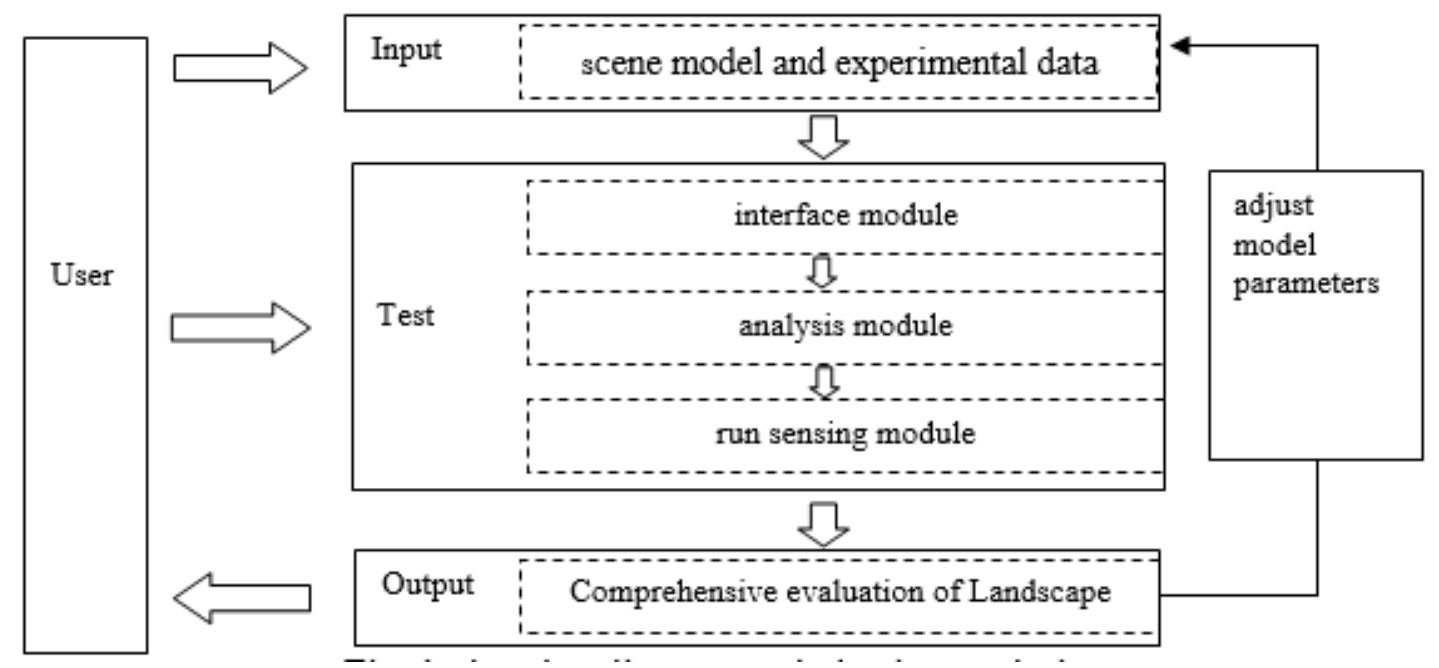

Fig. 1 virtual reality system in landscape design

\subsection{Virtual reality technology in landscape design is as follows.}

(1) At the preparatory stage of the project: According to the preliminary research work, in order to accurately grasp the site conditions, to ensure the project smoothly, the feasibility of the site can be analyzed based on virtual reality technology and other supporting technologies such as GIS technology. The internal elements of the site are modeled by the simulation such as topography, building, water and vegetation. Through the multiple perspectives and all-round observation and research, we are understanding the limitations of the site. As well as simulation of the local wind and sun provide the necessary preparations for site space for building, which offers scientific and effective support, for the designer's anticipation of the early stage.

(2) In the conceptual design phase of the project: Virtual reality technology can help designers to complete the conceptual design, building conceptual models in a virtual environment, with VR technology and equipment, making a comprehensive real-time dynamic analysis and get feedback through the sensory perception, so that the designer can grasp the overall relationship between composition and space to promote the creation of the scheme.

(3) In the detailed design phase of the project: Virtual reality technology can assist in the ultimate realization of design solutions through human-computer interaction with the accurate depiction of landscape scenes and the real-time generation of landscape scenes, designers can break the conventional design rules and make the real scene a more exaggerated deformation, to express abstract thinking, and a more poetic pursuit technically, making landscape design more innovative. At the same time, in the virtual scene, the landscape architecture can switch the different design schemes in real time, feeling different landscape in the same place or the same sequence, to get a best solution from the comparison of many schemes finally.

(4) In the stage of performance of the scheme: Public and policy makers can the whole process of generation with the virtual reality technology scheme, feeling the designer's design intention form an all-round multi-angle perspective freely and the real effect after the completion of the project, which offers a supporting impact on project's evaluation and suggestion.

(5) In the construction phase of the project: virtual reality technology can simulate the construction site, reasonably control and arrange the construction schedule to guide the whole process of the construction scientifically, so that we can effectively avoid security risks, improve project quality, shorten the construction period, and reduce the waste of materials etc.

\section{Augmented reality and Landscape architecture}

Designers can use augmented reality to virtualize landscape design solutions in 3D, directly obtaining the result of the project, to prove the feasibility of the scheme, avoid design risk, and improve the ability of multi-party cooperation. Augmented reality technology, characterized by its combination of virtual and reality, synchronization and natural interaction, combines the physical 
world with the virtual object, increase the sense of reality of the user experience, and implement the interaction of the senses to complete the feedback of the project modification.

The landscape augmented reality system (figure. 2) mainly inputs the completed landscape scene model into the virtual equipment, to complete the real-time rendering of the scene, also recording the real world pictures and videos. The virtual information is loaded into the real scene, the designer by wearing a helmet mounted display, tracking and locating the mark, to monitoring the location, view direction and movement the observer to help system real time display of virtual scene objects to complete the accurate registration virtual scene and real scene and to achieve consistency of shade and shadow, light, and realize the interaction witch nature with the interactive equipment at the same time [9]. Modify design plans in time by feedback information, achieving rationalization, accuracy and humanization of the program.

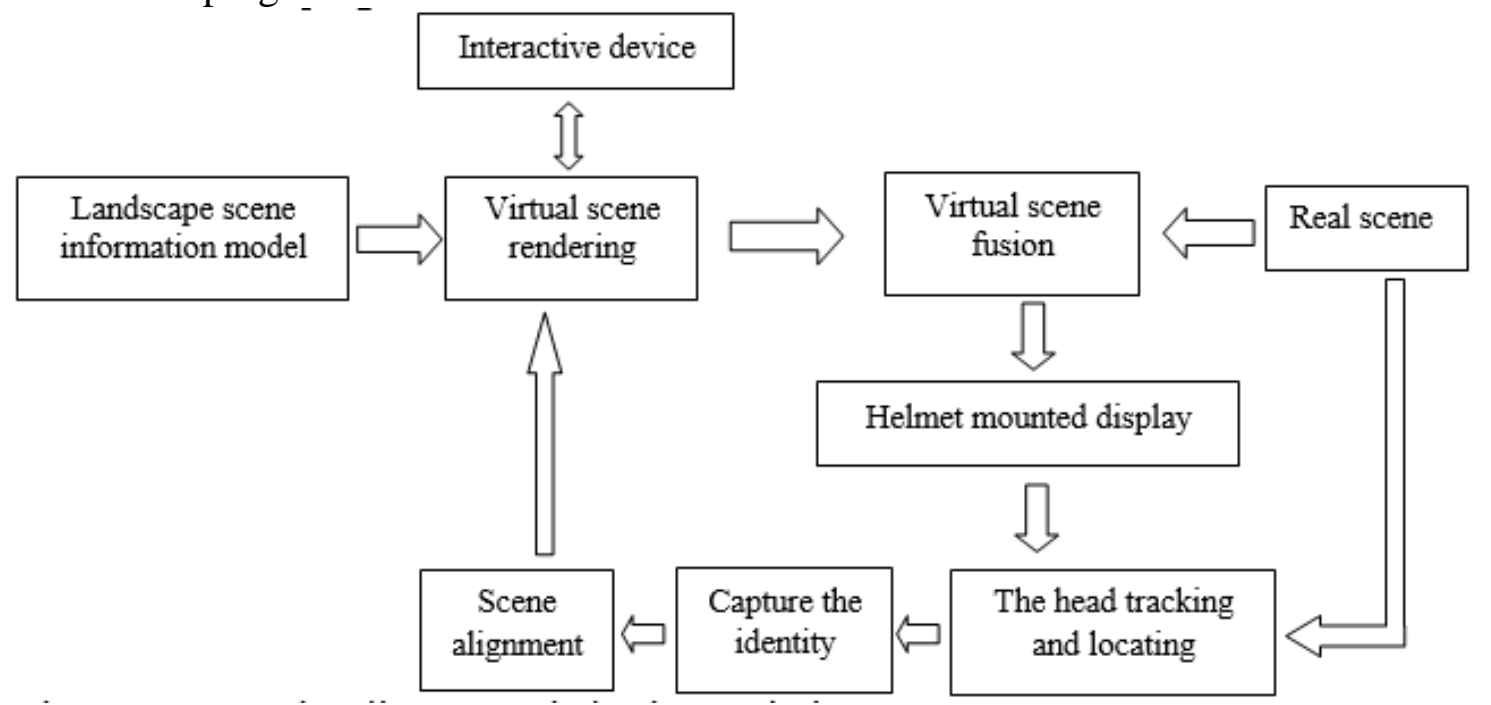

Fig. 2 Augmented reality system in landscape design

In landscape design, augmented reality technology mainly displays in two aspects, when one is in the project performance and plan report, AR technology can make the scheme presented to decision makers gradually according to the designer's willingness, generating the visual impact with strong technology People feel like being in the real world, which is beneficial for making a better evaluation for the project. Another is AR, through showing the scene and construction after transformation, can make users understand construction materials in time accurately, improve the accuracy of budget and control the project cost effectively, when the design painting is unsuitable for the facts and needs to be corrected.

\section{Mixed reality and Landscape architecture}

Compare with other two technologies, it can make virtual environment more intelligent, users can see the perspective holographic image of the object in real space, by wearing a helmet mounted display and interact with the virtual objects and in three-dimensional space, can make the corresponding adjustment to the scene according to the change of space, The preset data can be input into the system, and the best design scheme can be selected according to the fit of the specific material in the specific environment, thus shortening the design cycle and achieving the desired goal.

The landscape mixed reality system (Figure 3 ) is mainly composed of a virtual scene generation, tracking, positioning and interactive parts. In the virtual scene generation part, it is responsible for the modeling, generation and management of the landscape virtual scene; the tracking location focuses on the location of the user's walking position and the direction of sight, and completes the fusion of the virtual scene and the real world.; the interaction part is responsible for sensory signals and input and output of environmental signals, and the task of feedback, modification, and integration is completed to make the design more prefect. 


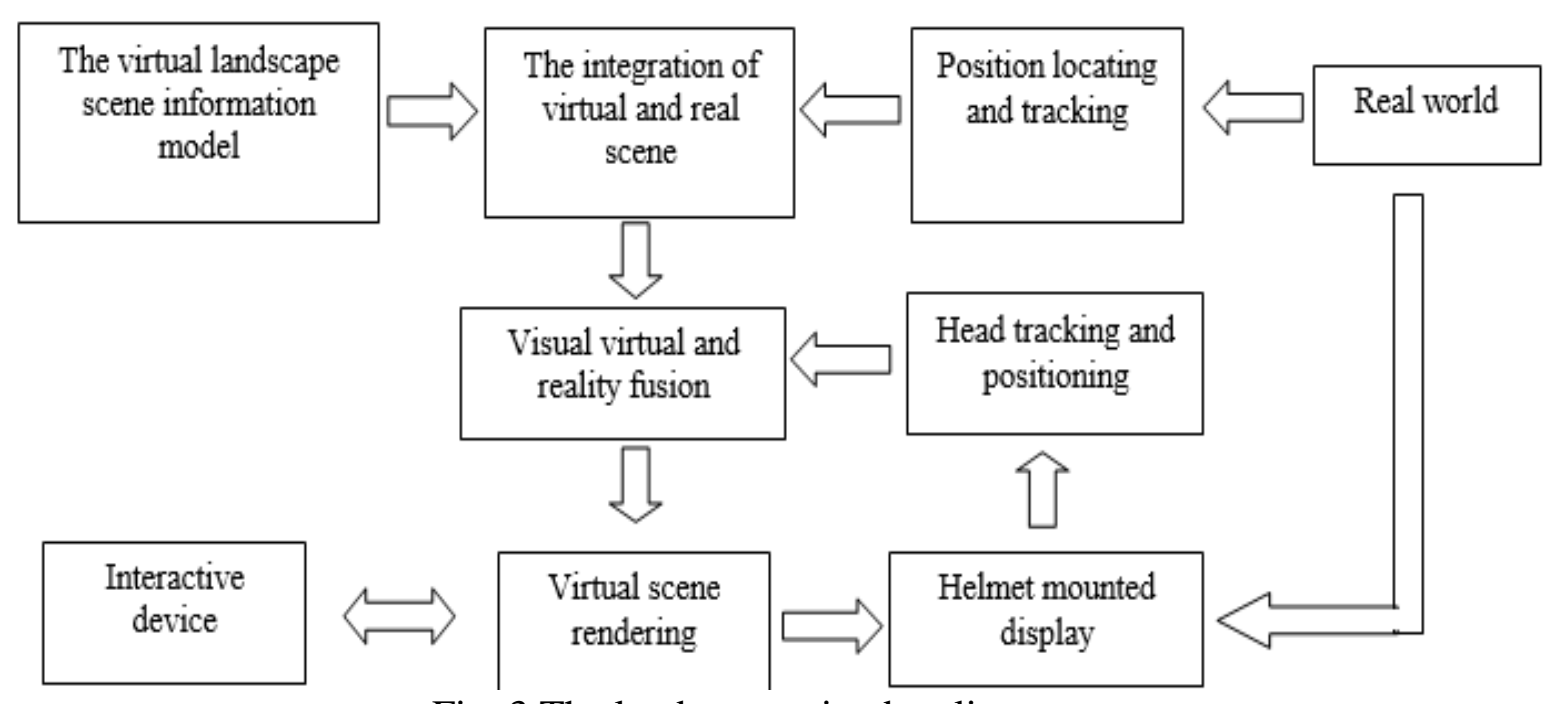

Fig. 3 The landscape mixed reality system

Mixed reality technology in the specific design of landscape architecture, the main performance of mixed reality technology is to provide the project progress chart for party A, the designers and the workers to discuss the feasibility of the design. The cost and the period of project management can be saved in order to improve the quality of the project, the team's ability to cooperate and the efficiency of the term. However, due to the limitations of the current technical level, it is only reflected in the landscape and small garden architecture design, according to the design needs, you can repeatedly evaluate and modify the shape of garden sketch, to the satisfaction, reduce the risk of product design, which is conducive to the construction of landscape sketch database. 


\section{The differences and integrated applications of VR, AR and MR technologies}

Table 1. Comparison of virtual reality, augmented reality and mixed reality technology

\begin{tabular}{|c|c|c|c|}
\hline & Virtual reality & Augmented reality & Mixed reality \\
\hline $\begin{array}{l}\text { The real } \\
\text { world and } \\
\text { the virtual } \\
\text { world } \\
\text { (Build } \\
\text { phase) }\end{array}$ & $\begin{array}{l}\text { The virtual reality world is } \\
\text { constructed on the basis of } \\
\text { realistic and cultural } \\
\text { characteristics; The virtual } \\
\text { world can be nonexistent in } \\
\text { reality }\end{array}$ & $\begin{array}{c}\text { Augmented reality virtual } \\
\text { world construction has } \\
\text { nothing to do with real world } \\
\text { entities }\end{array}$ & $\begin{array}{c}\text { The existence of the virtual } \\
\text { world has nothing to do with } \\
\text { the real world }\end{array}$ \\
\hline $\begin{array}{l}\text { The real } \\
\text { world and } \\
\text { the virtual } \\
\text { world } \\
\text { (Use } \\
\text { phase) }\end{array}$ & $\begin{array}{c}\text { There is only a virtual world, } \\
\text { no real world }\end{array}$ & $\begin{array}{l}\text { The real world coexists with } \\
\text { the virtual world; The real } \\
\text { world influences the virtual } \\
\text { world, but the virtual world } \\
\text { does not affect the real world }\end{array}$ & $\begin{array}{l}\text { The real world and the } \\
\text { virtual world interact with } \\
\text { each other and permeate } \\
\text { each other; you can move } \\
\text { from the virtual world into } \\
\text { the real world, or the real } \\
\text { world into the virtual world }\end{array}$ \\
\hline $\begin{array}{l}\text { The virtual } \\
\text { world and } \\
\text { the spiritual } \\
\text { world }\end{array}$ & $\begin{array}{l}\text { Users immerse themselves in } \\
\text { a virtual world built by } \\
\text { artificial devices and react to } \\
\text { it }\end{array}$ & $\begin{array}{l}\text { Virtual worlds built by } \\
\text { artificial devices are stacked } \\
\text { in the real world and } \\
\text { presented to users; The user } \\
\text { can control the virtual world }\end{array}$ & $\begin{array}{l}\text { Users immerse themselves in } \\
\text { a virtual world and a real } \\
\text { world built by artificial, It is } \\
\text { also true and false; the user } \\
\text { can control the virtual world }\end{array}$ \\
\hline $\begin{array}{l}\text { The real } \\
\text { world and } \\
\text { the spiritual } \\
\text { world }\end{array}$ & Irrelevant & $\begin{array}{l}\text { The real world is presented } \\
\text { directly to the user; Users } \\
\text { can't control the real world }\end{array}$ & $\begin{array}{l}\text { The real world is presented } \\
\text { directly to the user; users } \\
\text { can't control the real world, } \\
\text { and distinguish between the } \\
\text { real and the virtual world by } \\
\text { themselves }\end{array}$ \\
\hline $\begin{array}{l}\text { Working } \\
\text { principle }\end{array}$ & $\begin{array}{l}\text { The use of computer } \\
\text { technology and equipment to } \\
\text { simulate a 3D virtual world, } \\
\text { to provide users with the } \\
\text { simulation of visual, tactile } \\
\text { and auditory, you can observe } \\
\text { and experience the virtual } \\
\text { world in time ; with emphasis } \\
\text { on the reality of the } \\
\text { simulation instead of } \\
\text { enhancement }\end{array}$ & $\begin{array}{l}\text { The computer generated } \\
\text { virtual objects or system } \\
\text { information superimposed on } \\
\text { the real scene, and to complete } \\
\text { the implementation of } \\
\text { interactive, real enhancement; } \\
\text { emphasize the real-time } \\
\text { capability of the virtual scene } \\
\text { with virtual annotation and } \\
\text { enhancement of reality }\end{array}$ & $\begin{array}{l}\text { Combined with the real } \\
\text { world and the virtual world } \\
\text { to create a new visualization } \\
\text { environment, physical and } \\
\text { digital objects coexist, and } \\
\text { implement real-time } \\
\text { interaction to simulate the } \\
\text { real object; emphasizes } \\
\text { interactivity between the real } \\
\text { and the virtual worlds }\end{array}$ \\
\hline $\begin{array}{l}\text { Main } \\
\text { platform } \\
\text { equipment }\end{array}$ & $\begin{array}{c}\text { Oculus Rift; HTC Vive; } \\
\text { Samsung Gear VR ; Sony } \\
\text { Play Station VR; Storm } \\
\text { mirror }\end{array}$ & $\begin{array}{c}\text { Google Tango and Google } \\
\text { glass; Microsoft HoloLens; } \\
\text { Sony PlayStation; }\end{array}$ & Magic Leap \\
\hline $\begin{array}{l}\text { Main } \\
\text { application } \\
\text { area }\end{array}$ & $\begin{array}{l}\text { Military, Aerospace, Health } \\
\text { care, Urban Planning, Culture } \\
\text { and Art, Real estate as well as } \\
\text { education and business }\end{array}$ & $\begin{array}{l}\text { Games, Medical, municipal } \\
\text { construction planning, } \\
\text { engineering design, } \\
\text { Sophisticated weapons } \\
\text { research and development, } \\
\text { remote robot control and } \\
\text { virtual shopping }\end{array}$ & $\begin{array}{l}\text { Emotional healing, } \\
\text { Business, movies, } \\
\text { Environmental design, } \\
\text { Shopping }\end{array}$ \\
\hline
\end{tabular}

The chart above shows that virtual reality, augmented reality and mixed reality technology are different in the use and application phase of the virtual world, and their working principle and use of the platform. All three perceive the external world (the virtual world and the real world) in the spiritual world through the human-computer interaction devices and make a corresponding response to the stimulation of the outside world. The progressive relationship of these three technologies can be 
understood as such: Virtual reality > Augmented reality > Mixed reality > Reality. In realistic applications, due to technical imperfections, there will be a lot of drawbacks. In virtual reality technology, the helmet display device is too heavy, so users will appear motion sickness after a long-time wearing; with much emphasis on visual impact, the technology ignores the sense of hearing and tactile perception; The characteristics of the enterprise equipment $\mathrm{R} \& \mathrm{D}$ platform poor compatibility, brought great distress to the users; The equipment also has an obvious disadvantage in mobility. Augmented reality also shows the inaccuracy of real-time processing technology and the real world in calibration. The popularity of 3D registration technology is not enough and pays more attention to the ability and ignore the mobility of devices. There is also technically short board in the development of mixed reality technology. This requires the government department's support, innovation and collaboration among enterprises and participation from all walks of life, working together to develop virtual appropriate technical equipment, complete technology innovation, and promote the popularization of the virtual technology.

Augmented reality and virtual reality are committed to building a realistic environment of sensory input. The difference is that virtual reality inputs virtual signal, to create a virtual environment with realistic feeling by shielding the reality, so the key technology is the realistic modeling; and augmented reality is the input real signal, form a sense of reality therefore, accurate positioning of reality is the key technology [10]. Virtual reality has a slightly lower requirement in terms of technical level and the corresponding velocity than the mixed reality, when simulating an object, MR simply make a physical simulation, while VR will simulate the physical and its surrounding environment, which means a larger workload. It is possible to say that VR is just $100 \%$ covering the virtual part of MR, and VR devices are just a transitional phase of MR devices, which can essentially implement the content of VR. To some extent, the AR is regarded as another form of MR, but they still have the difference. For the relative position of the virtual objects, VR devices will follow the movement of the mobile devices, while MR remained relatively stable state. Ideally, AR can distinguish between virtual objects and real objects, but MR cannot achieve this function.

By contrast, compared with AR and MR in the field of landscape design, the use of virtual reality technology is more feasible with advantage over mature technology, complete equipment low cost, which can be application to the whole process of landscape design, including prophase research, conceptual design and detailed design stage and implementation stage of project.

\section{Conclusion}

The innovation of technology has provided a lot of convenience for human development. With the coming of the digital era, digital technology provides more scientific and accurate support for the construction of landscape. The emergence of virtual reality technology brought great reform for the landscape design industry, the substance and information function of landscape architecture are separately given to different carrier, so that the information oriented landscape architecture becomes visualized, which makes the garden form has been further improved, with less expensive and more perfect equipment, more processing power and higher quality graphics to change the landscape design field as a subtle influence gradually. At the same time, augmented reality and mixed reality technology change the mortal life and other sciences and technology fields in a more innovative way. However, its combination with the landscape design still needs a more comprehensive technical support. It is believed that with the rapid development of computer and digital information technology, and creative research from relevant departments, the virtual technology will be more widely applied to landscape design fields, and play a necessary supporting role in the development of landscape design. 


\section{References}

[1]. Hongjian Liao. Somatosensory interaction design and its application in 3D virtual experiment [M]. Journal of distance education, 2013.

[2]. Wei Yi. Gartner predicts ten big technology trends in 2017: www.vrcnfun.com/vrvr/3878/s1.ht $\mathrm{ml}$.

[3]. Ying Zhang. Virtual reality technology overview [J]. Knowledge economy, 2016.

[4]. Jiayuan Lu. A roaming VR Virtual Library Based on the "three networks in one" environment [J]. Journal of Yulin Normal University, 2013.

[5]. Songlin Zhu. An analysis of Augmented Reality application and developmental disorders in paper publishing. [J]. Technology and publication, 2014.

[6]. Yan Li. An analysis of the narrative structure of "virtual reality" science fiction film [J]. Journal of Huaihai Institute of Technology: Social Sciences Edition, 2011.

[7]. Weihua Xu. From virtual reality technology to augmented reality technology [J]. China cable TV, 2013.

[8]. Shangjiao Zhang. The application of virtual reality technology in automotive industry [J]. Automotive technology, 2004.

[9]. Yuanzhu Fan. Research the application technology of augmented reality [D]. Zhejiang University, 2008.

[10]. Jing Jing. What is the difference between augmented reality and virtual reality? : www.blog.sna. com.cn/s/blog_75b5c04b0102wsfl.ht. 